RESEARCH

\title{
Methylation Analysis of a Marsupial X-linked CpG Island by Bisulfite Genomic Sequencing
}

David A.F. Loebel and Peter G. Johnston ${ }^{1}$

\author{
School of Biological Sciences, Macquarie University, New South Wales, Australia, 2109
}

\begin{abstract}
Paternal $\mathrm{X}$ chromosome inactivation occurs in rodent extraembryonic membranes and in all tissues of marsupials. Methylation of $\mathrm{CpG}$ islands occurs on the inactive $X$ in eutherians and is considered to be a stabilizing mechanism. The only previous study of a marsupial X-linked $\mathrm{CpG}$ island was of the G6PD gene of the Virginia opossum, in which the paternally derived allele is not completely repressed. We have cloned the $5^{\prime}$ end of the G6PD gene from an Australian marsupial, the common wallaroo, and sequenced the associated CpG island. The paternally derived G6PD allele is completely repressed in tissues of this species. Methylation analysis using $\mathrm{Hpall}$ and $\mathrm{Cfol}$ restriction enzymes and bisulfite genomic sequencing of $47 \mathrm{CpG}$ dinucleotides in a 613-bp region reveals hypomethylation of male and female DNA from tissues, cultured fibroblasts (in which the paternal allele is partially expressed) and sperm. This suggests that methylation of CpG islands is not required for maintenance of $X$ inactivation in marsupials even where repression of the paternal allele is complete.
\end{abstract}

Dosage compensation by $\mathrm{X}$ chromosome inactivation occurs in both eutherian (placental) and metatherian (marsupial) mammals. In eutherians inactivation of either $\mathrm{X}$ chromosome occurs at random in female embryos and is stably maintained. In the extraembryonic endoderm of rodents the paternally derived $\mathrm{X}$ chromosome is inactivated (West et al. 1977). The paternally derived $\mathrm{X}$ chromosome is always preferentially inactivated in marsupials (Sharman 1971).

$\mathrm{X}$ inactivation in marsupials is less complete than in eutherians. In marsupials, $X$ inactivation occurs in a tissue-specific fashion, and the activity state of paternally derived alleles varies for different genes and in different species. For example, in the Virginia opossum (Didelphis virginiana), a North American marsupial, there is detectable activity of the paternal allele of glucose6-phosphate dehydrogenase (G6PD) in all tissues studied (VandeBerg et al. 1987). In contrast, subspecies crosses between the Australian common wallaroo and euro (Macropus robustus robustus and Macropus robustus erubescens) show no detectable activity of the paternally derived G6PD allele in any adult tissue except cultured fibroblasts (VandeBerg et al. 1987).

Methylation of cytosines at $\mathrm{CpG}$ dinucleotides within $\mathrm{CpG}$ islands occurs on the inactive

'Corresponding author.

E-MAIL pjohnsto@rna.bio.mq.edu.au; FAX 6128509686.
$\mathrm{X}$ chromosome in eutherians. Early evidence for a direct role of DNA methylation in X inactivation was obtained from studies in which 5-azacytidine was shown to cause reactivation of previously inactive hypoxanthine phosphoribosyltransferase (HPRT) alleles in cultured humanmouse somatic cell hybrids and mouse embryonal carcinoma cell lines (for review, see Singer-Sam and Riggs 1993). Studies utilizing methylation-sensitive restriction enzymes have demonstrated that $\mathrm{CPG}$ islands on the inactive $\mathrm{X}$ are more highly methylated than those on the active $\mathrm{X}$ at the housekeeping loci HPRT, phosphoglycerate kinase 1 (PGK-1), and G6PD (SingerSam and Riggs 1993). Methylation analysis using 13 probes that detected $\mathrm{X}$-linked $\mathrm{CpG}$ islands showed that, except at two putative pseudoautosomal loci, the majority of rare cutter restriction enzyme sites were methylated on the inactive but not the active $X$ (Norris et al. 1991). The investigators concluded that methylation of $\mathrm{CpG}$ islands is a general feature of $\mathrm{X}$ inactivation.

It has been suggested that methylation of critical sites, rather than the overall pattern of methylation, may be important in maintaining $X$ inactivation (Hansen et al. 1988). Single informative restriction sites that are always methylated on the inactive but not the active $X$ have been described in the CpG islands of the $P g k-1$ and G6pd genes (Singer-Sam et al. 1990; Toniolo et al. 1991). The HpaII site in the Pgk-1 promoter re- 


\section{METHYLATION ANALYSIS OF WALLAROO G6PD}

gion becomes methylated in the preimplantation embryo, beginning at -3.5 days postconception (dpc), whereas the G6pd HpaII site becomes methylated postimplantation at $5.5 \mathrm{dpc}$ (Grant et al. 1992). Methylation of the critical sites on the inactive allele occurs in both the embryonic lineages, where $\mathrm{X}$ inactivation is random, and in the extraembryonic endoderm, where paternal $\mathrm{X}$ inactivation occurs. In the germ line the critical sites remain unmethylated in both males and females throughout development (Grant et al. 1992).

More detailed analysis of methylation patterns has been possible using genomic sequencing methods that do not rely on the presence of restriction enzyme sites and can therefore be used to determine the methylation status of many more CpG dinucleotides (Grigg and Clark 1994). The CpG islands associated with the human and mouse $P G K-1 / P g k-1$ genes have been studied using a chemical cleavage-based genomic sequencing protocol (Pfeiffer et al. 1990; Tommasi et al. 1993). The human PGK-1 gene is methylated on the inactive $\mathrm{X}$ chromosome at 61 of 62 CpGs (Pfeiffer et al. 1990). In contrast, the $P g k-1$ gene in mice is methylated to a much lower extent, and only the single potentially critical site is fully methylated on the inactive X (Tommasi et al. 1993). The human HPRT gene has been analyzed both by the chemical cleavage method of genomic sequencing and by the more recently described bisulfite genomic sequencing technique (Frommer et al. 1992; Clark et al. 1994). Analysis with both methods demonstrated that the CpG island region is highly methylated on the inactive X (Hornstra and Yang 1994; Park and Chapman 1994); however, the bisulfitebased technique provided determination that the degree of methylation is heterogeneous within tissues (Park and Chapman 1994).

Only one marsupial CpG island has been examined previously for methylation. No differential methylation was detected at $\mathrm{HpaII}$ or $C f o \mathrm{I}$ restriction sites in the $5^{\prime} \mathrm{CpG}$ island of the G6PD gene of D. virginiana (Kaslow and Migeon 1987). The investigators proposed that the lack of DNA methylation on the inactive $X$ in marsupials accounts for the less complete form of $\mathrm{X}$ chromosome inactivation. They suggested that DNA methylation in CpG islands is a stabilizing mechanism in eutherians that is not present in marsupials. Although the conclusions of Kaslow and Migeon (1987) have been accepted widely, promoter methylation has not been studied in any other loci or in any species with complete repression of the paternal allele. In addition, many potential sites of methylation are not within restriction sites. Since the existence of critical sites has been postulated in humans and mice (Hansen et al. 1988), and given the comparative hypomethylation of mouse inactive $X$ CpG islands, it is possible that only one or a few CpG sites are responsible for maintaining $\mathrm{X}$ inactivation in marsupials.

The full cDNA for G6PD from M. r. robustus has been cloned recently (Loebel et al. 1995), including the $5^{\prime}$ untranslated region. This region shows characteristics of a CpG island, as do the corresponding regions of the eutherian G6PD genes. We have used the M. r. robustus G6PD cDNA to isolate a genomic $\lambda$ clone containing the 5 ' end of the G6PD gene to study the methylation status of the CpG island on the active and inactive $\mathrm{X}$ chromosomes using the bisulfite-mediated genomic sequencing protocol.

\section{RESULTS}

\section{Cloning of the $5^{\prime}$ CpG Island}

One positive clone $(\lambda 12 \mathrm{~B} 4)$ was obtained after screening $5 \times 10^{5}$ plaques from the unamplified $\lambda$ genomic library using a PCR product amplified from exons 2-5 of $M$. r r robustus G6PD cDNA (Loebel et al. 1995). A clone containing exons 1 and 2 of the M. r. robustus G6PD cDNA (Loebel et al. 1995) hybridized to a 1.1-kb BglII-HindIII fragment and a $4.2-\mathrm{kb} B g l I I$ fragment within $\lambda 12 \mathrm{~B} 4$ (Fig. 1). The 4.2-kb BglII fragment was also detected by an oligonucleotide probe specific to exon 2. Clones containing the 1.1-kb BglIIHindIII fragment (pBH1.1) were sequenced, revealing a region with the characteristics of a $\mathrm{CpG}$ island. Analysis of the sequence with CPGPLOT determined that a CpG island of $\sim 500-600$ bp was present within this clone (Fig. 2). Restriction mapping and partial sequencing of subclone pBH1.7, containing the 1.7-kb BglII-HindIII fragment immediately upstream of pBH1.1, revealed a region of $\sim 300$ bp with CpG island-like characteristics contiguous with the $5^{\prime}$ end of pBH1.1. The CpG island appears to be divided into two parts, the majority contained within $\mathrm{pBH} 1.1$ and separated from a second, smaller region farther upstream, within the pBH1.7 subclone, by a region of lower $\mathrm{G}+\mathrm{C}$ content. Figure 2 demonstrates the clear bimodality of the $\mathrm{CpG}$ island. 
LOEBEL AND JOHNSTON

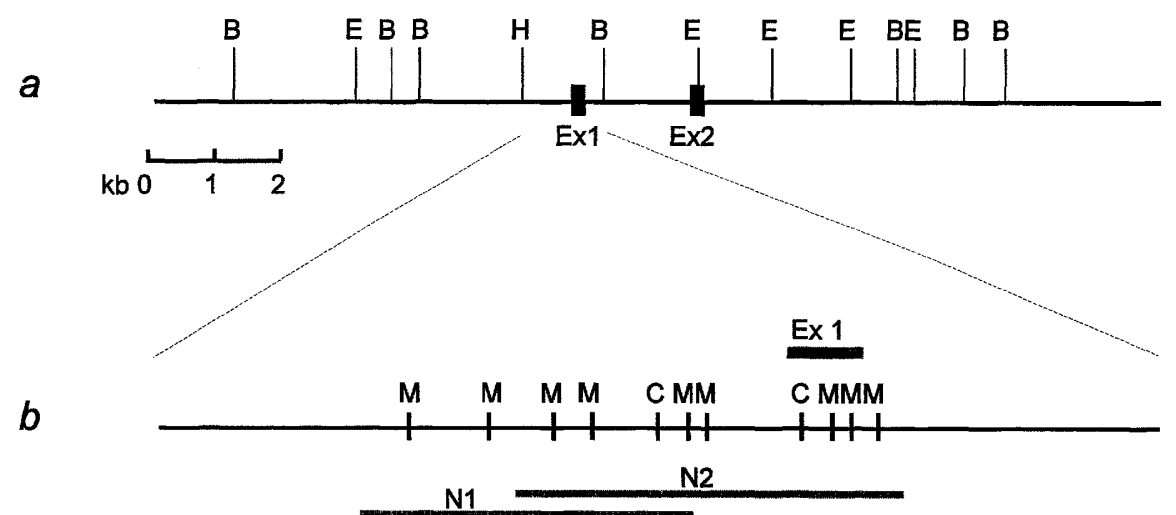

$c$

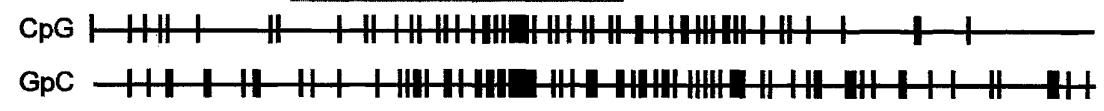

Figure 1 (a) Restriction map of $\lambda 12 \mathrm{~B} 4$ showing locations of restriction sites for BgIII (B), EcoRI (E), and HindIII (H). Locations of exons 1 and 2 are shown by shaded boxes. (b) Map of all Mspl-Hpall sites (M) and Cfol (C) sites in the 1.1-kb BgIll-HindIII fragment containing exon 1. The bar above the restriction map indicates the location of exon 1, at the $3^{\prime}$ end of the CpG island. (c) Map of all $\mathrm{CpG}$ and $\mathrm{GpC}$ dinucleotides in the 1.1-kb Bgll-Hindlll fragment. Bars show the regions included in genomic sequencing analysis. (N1) The region amplified by nested primer set 1; (N2) the region amplified by nested primer set 2 .

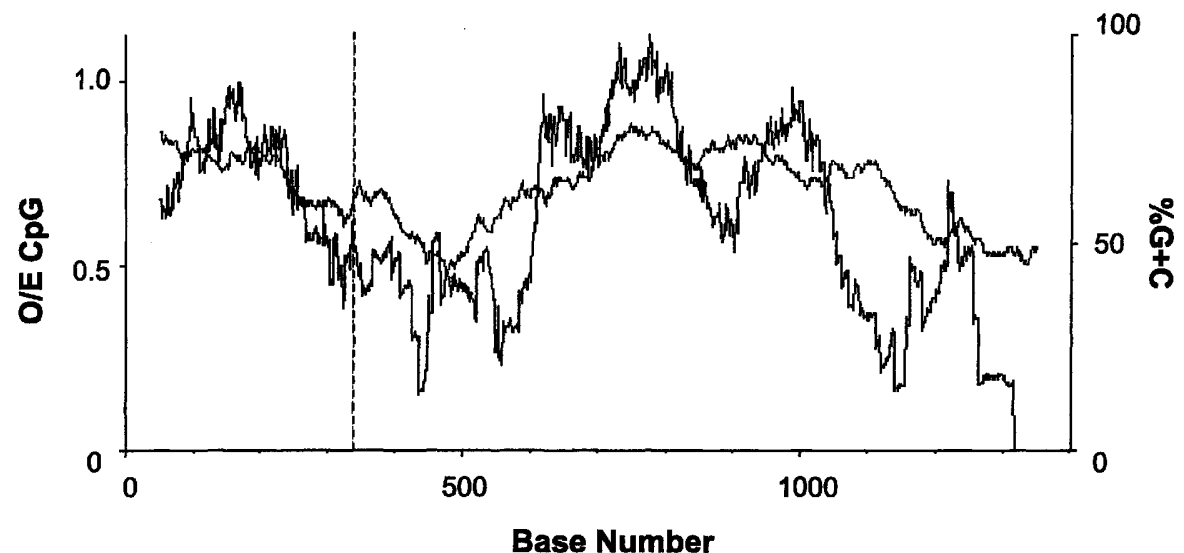

Figure 2 Plot of ratio of observed/expected $\mathrm{CpG}$ frequency (solid line) and percent $G+C$ (shaded line) of the two $C p G$ island regions. Analysis was performed using the program CPGPLOT, based on the methods of GardinerGarden and Frommer (1987) and accessed through the Australian National Genome Information Service (ANGIS). CpG islands are defined by the CPGPLOT program as having a moving average of observed over expected $\mathrm{CpG}>0.6$ and a moving average of percent $G+C>0.5$. Average values are plotted using a 100-bp window moving in 1-bp increments. The broken vertical line indicates the HindlII site dividing the clones $\mathrm{pBH} 1.7$ and $\mathrm{pBH} 1.1$.

Exon 1 was located by comparison to the cDNA sequence (Loebel et al. 1995; see Fig. 1). The $\mathrm{G}+\mathrm{C}$ content and observed/expected CpG ratio fell below those expected for a typical CpG island immediately after the intron-exon boundary.

\section{Methylation Analysis by Southern Blotting}

Initially, the methylation status of the CpG island was analyzed using the pBH1.1 clone as a probe against Southern blots of genomic DNA from liver, kidney, spleen, brain, lung, and heart tissues of male and female M. r. robustus. DNA was digested initially with $B g l I I$ and HindIII, followed by either MspI (restriction site CCGG, not sensitive to cytosine methylation), HpaII (restriction site also CCGG, sensitive to methylation of the internal cytosine), or CfoI (restriction site GCGC, sensitive to methylation of the internal cytosine). Probing of HpaII-digested DNA revealed two major bands in all male and female tissues corresponding to the largest MspI fragments predicted from the sequence (Fig. 3A). No larger fragments corresponding to methylated DNA were visible. Many of the smallest fragments predicted from DNA sequencing were not visible on autoradiographs. Two bands corresponding to the largest CfoI fragments could be visualized (Fig. 3B), but the third smaller fragment was not visible.

Because the only fragments visible in both the HpaII and CfoI digests corre- 
METHYLATION ANALYSIS OF WALLAROO G6PD

A

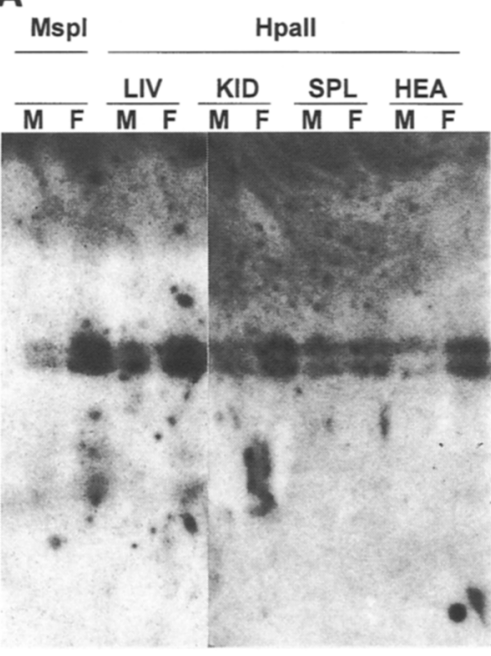

B

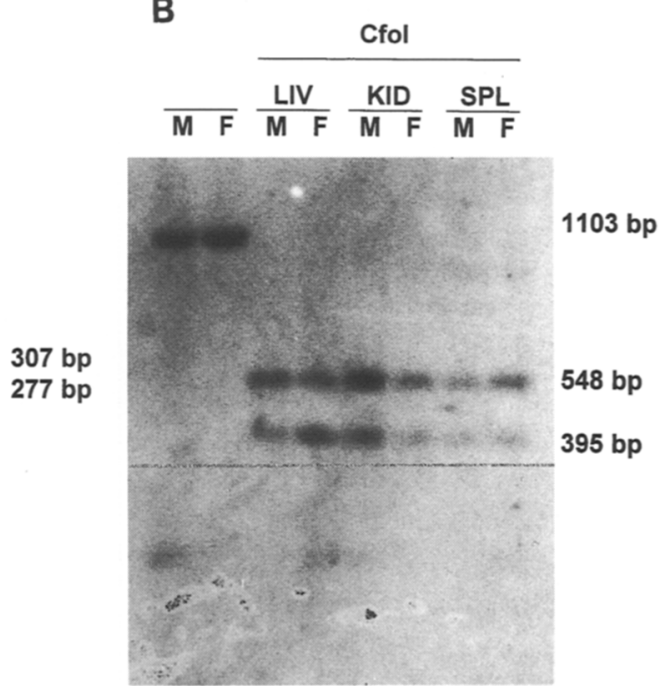

Figure 3 Autoradiographs of M. r. robustus genomic DNA from male (M) and female $(F)$ tissues probed with $\mathrm{pBH}$ 1.1. DNA was initially digested with $B g / l$ and HindIII. (A) DNA was subsequently digested with Mspl or Hpall and size fractionated on a $2 \%$ agarose gel. The largest fragments visible correspond to the 307-bp and 277-bp Mspl fragments predicted from DNA sequencing. (B) DNA was either subjected to no further digestion (lanes 1,2) or digested with Cfol. Digested DNA was size fractionated in $1.5 \%$ agarose. The visible fragments correspond to the 548-bp and 395-bp fragments predicted from the DNA sequence. Tissues shown are liver (LIV), spleen (SPL), kidney (KID), and heart (HEA).

sponded to those that would be expected if no methylation were present in the region, it appeared that the CpG island was largely unmethylated. However, because a large number of $\mathrm{HpaII}$ sites are present in this region, giving rise to small (some 50 bp or less) fragments, it could not be determined whether all HpaII sites were unmethylated in all samples. Many CpG dinucleotides are not within restriction sites; therefore, it was possible that differential methylation was present but could not be detected by Southern blotting.

\section{Bisulfite-mediated Genomic Sequencing}

A region of $613 \mathrm{bp}$ within the $\mathrm{CpG}$ island, beginning 460 bp upstream of exon 1 and continuing $69 \mathrm{bp}$ into the first intron, was analyzed by bisulfite genomic sequencing in two overlapping regions (Fig. 1). Efficient conversion, as determined by PCR product yield and direct sequencing of products, was obtained most reliably by incubating the conversion reaction in a thermal cycler at $55^{\circ} \mathrm{C}$, with a denaturing step $\left(94^{\circ} \mathrm{C}\right.$ for 1.5-3 min) every $3 \mathrm{hr}$. Sufficient amounts of PCR product for sequencing and cloning were ob- tained with nested PCR reactions, where $2-5 \mu$ l of the first round amplification was used as a template for a second $25-\mu$ reaction with primers located internal to those used in the firstround amplification.

PCR-amplified products were sequenced directly to determine the average methylation status of individual $\mathrm{CpG}$ dinucleotides. A control conversion was performed on pBH1.1 DNA grown in bacterial strain $\mathrm{DH} 5 \alpha$, a $d \mathrm{~cm}^{+}$ host strain. The methylation status of three EcoRII sites within the region amplified by nested primer set 2 was determined. The internal cytosines within all three EcoRII sites appeared highly methylated. Two of these sites are shown in Figure 4 . The product was cloned, and sequence obtained from nine clones. Two clones appeared largely unconverted; however, in other clones the only unconverted cytosines were within EcoRII sites. The three sites were methylated in $6 / 7,6 / 7$, and $5 / 7$ clones. This showed that the region did not contain sequence that was intrinsically resistant to bisulfite conversion and acted as a control to check for plasmid contamination of the experimental reactions, because EcoRII sites were not expected to be methylated in mammalian genomic DNA.

Direct sequencing of amplified products revealed no detectable unconverted cytosines in tissues (liver, spleen, or brain), cultured cells, or sperm DNA (Fig. 5). PCR products amplified by both nested primer sets from male and female liver DNA were cloned, and 10 clones of each product were sequenced. In the region amplified by nested primer set 1 , no unconverted cytosines were detected in either male or female DNA. A low level of apparent methylation of CpGs was observed in male and female samples in the region amplified by nested primer set 2 (Fig. 6). More unconverted cytosines were observed in female DNA than in male DNA, (seven methylated CpGs over 10 clones in female liver DNA, com- 


\section{LOEBEL AND JOHNSTON}

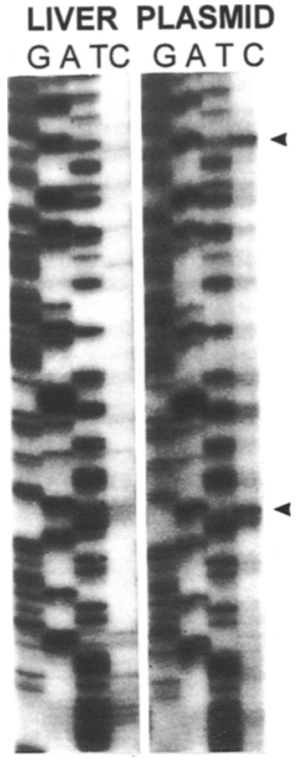

Figure 4 Comparison of methylation status of tissue and control plasmid DNA. Bisulfite converted female $M$. $r$. robustus liver and control $\mathrm{pBH} 1.1$ plasmid DNA were amplified with nested primer set 2. Products were sequenced with the fmol cycle sequencing kit (Promega) following size fractionation on $1.5 \%$ agarose. Arrowheads point to cytosines within EcoRII sites that are highly methylated in plasmid but not liver DNA. The sequence of the region shown is CCCTCСТCCCTGAAGCGCAGGTGCGGAATCCCAGGTCTGGATCGGAGCCAAAGC CGGGGGAGGCAGGGAGGGCCGGGGCGGAGTCAGGGGCCAACGGGCTGGGCCAGGGGGCGGAGATGGGGA. EcoRII sites are underlined.

pared with one in male DNA). Of 10 clones, 5 contained at least one unconverted cytosine; however, individual cytosines remained unconverted in a maximum of $2 / 10$ clones. A total of two unconverted cytosines outside CpG dinucleotides were detected in all 40 clones sequenced.

\section{DISCUSSION}

In this report we present the results of methylation analysis of DNA from male and female $M$. $r$. robustus using methylation-sensitive restriction enzymes and genomic sequencing analysis for 47 $\mathrm{CpG}$ dinucleotides within the $\mathrm{CpG}$ island in the $5^{\prime}$ region of the G6PD gene of $M$. r. robustus. The only previous study of methylation of a marsupial X-linked CpG island was in an American species that exhibits significant levels of expression of the paternal allele in all somatic tissues (Kaslow and Migeon 1987). The investigators found no evidence of sex-specific methylation differences in a CpG island $5^{\prime}$ to exon 2 of the
G6PD gene of $D$. virginiana. This study extends those previous findings to a distantly related marsupial species with complete paternal repres-

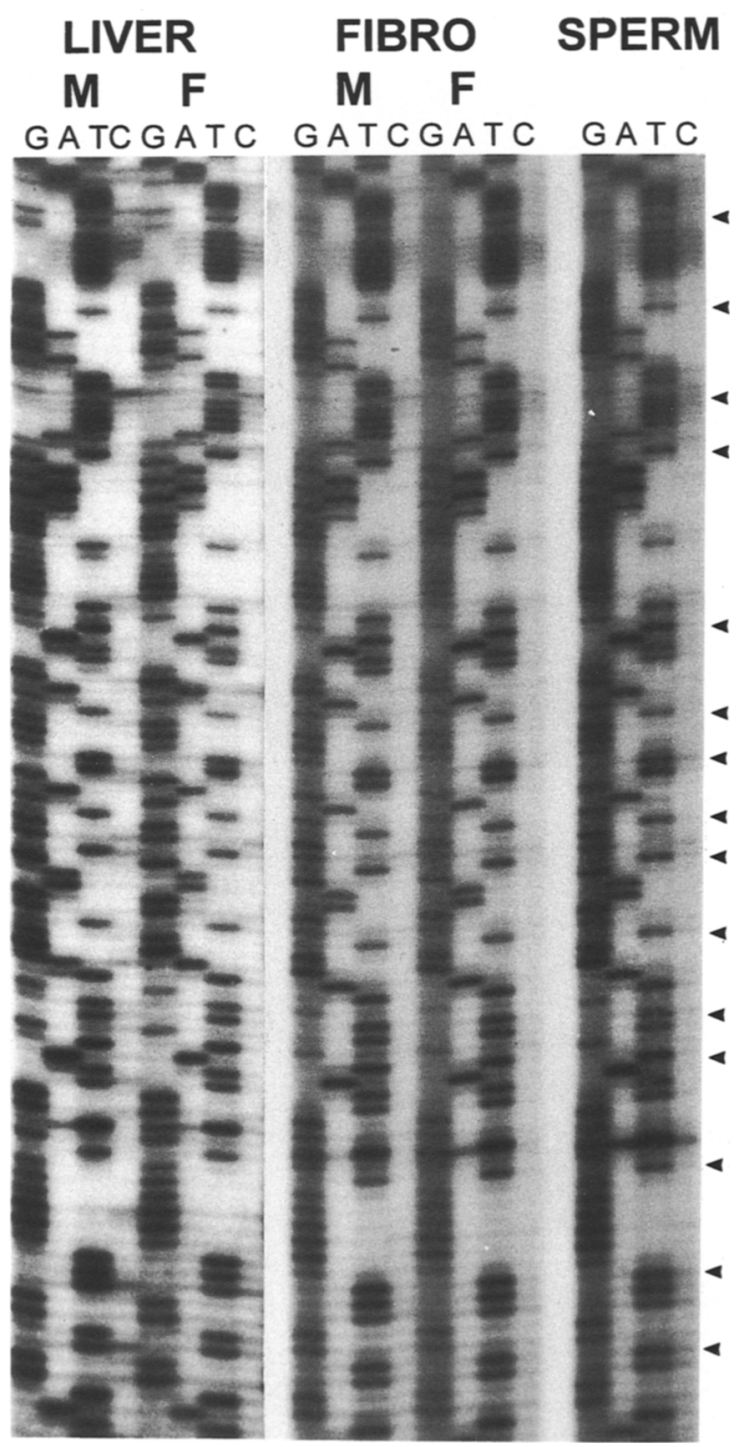

Figure 5 Methylation status of tissue (liver), cultured fibroblast, and sperm DNA. Bisulfite-treated DNA was amplified with with nested primer set 2, size fractionated, and sequenced with the fmol cycle sequencing system (Promega). Arrowheads point to $\mathrm{CpG}$ dinucleotides. Methylation was not detected in any tissue, fibroblast, or sperm sample. Faint bands are probably artifactual, as they do not necessarily correspond to cytosines in the original sequence and no non-CpG methylation was detected by sequencing clones. The sequence of the region shown in the figure is GGGGGGCGTGGCCACGTCGCAGGCGGAAGCGGCGAGCCGGGCGAGGC CACGTGGGGGTGGGAGAGAGCGATCTCGCTTGAGGAGGCGGGCCСTCCTCCCTGAAGCGCAGGTGCGGAA 


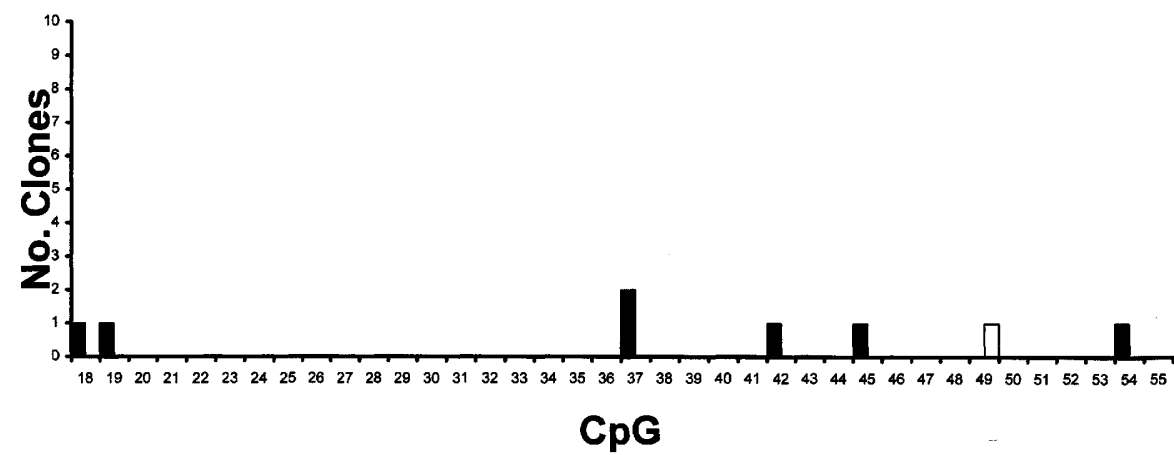

Figure 6 Methylation profile of $\mathrm{CpG}$ dinucleotides in the product amplified by nested primer set 2 . Ten clones each of PCR products, amplified with nested primer set 2, from bisulfite converted male and female liver genomic DNA were sequenced. Solid bars represent female; open bars represent male.

to be divided into two sections. This bimodal distribution of CpG density may indicate that there is another unidentified gene farther upstream. However, CpG islands that are divided have been described previously. Gardiner-Garden and Frommer (1987) describe a CpG island associated with the mouse int-1 that is highly fragmented and could be considered as three separate $\mathrm{CpG}$ islands. The $\mathrm{CpG}$ island associated with the mouse G6pd gene (Toniolo et al.

sion of the G6PD gene in tissues but partial paternal expression in cultured fibroblasts. The use of a genomic sequencing technique in addition to Southern blotting has allowed a far greater number of $\mathrm{CpG}$ dinucleotides to be analyzed than would be possible using restriction enzymes alone.

The M. r. robustus CpG island described here overlaps the start of transcription of the G6PD gene as determined by RACE (rapid amplification of cDNA ends)-PCR (Loebel et al. 1995). The characteristic high observed/expected CpG ratio ends in the first intron, within $100 \mathrm{bp}$ of the exon-intron boundary. The sequence of the CpG island shows little conservation between species. The M. $r$. robustus G6PD CpG island is a typical CpG island, as in humans, but the corresponding region in the mouse has a much reduced $\mathrm{G}+\mathrm{C}$ and CpG content (Toniolo et al. 1991). Regions have been identified that are highly conserved among human, mouse, and rat sequences (Toniolo et al. 1991; Rank et al. 1994). Only one of these regions was recognizable in $M$. r. robustus. A box $29 \mathrm{bp}$ long, located $252 \mathrm{bp}$ upstream of exon 1 (345 bp in mouse and $384 \mathrm{bp}$ in human), is $62.2 \%$ homologous between the wallaroo and mouse sequences and $73.7 \%$ homologous between the wallaroo and human sequences (Fig. 7). The human and mouse CpG islands continue farther into the first intron than in $M$. r. robustus G6PD. The single HpaII site that is always methylated on the inactive $\mathrm{X}$ in mouse and human occurs within the CPG island, 150 bp downstream of exon 1. In M. r. robustus, this region is relatively $\mathrm{CpG}$ poor, and not part of the $\mathrm{CpG}$ island.

The M. r. robustus G6PD CpG island appears
1991) has a generally lower CpG content and a distribution of CpG dinucleotides consisting of several small peaks.

Methylation analysis using methylationsensitive restriction enzymes and Southern blotting resulted in detection of only fragments that resulted from complete digestion by HpalI and $C$ foI. However, smaller fragments predicted from the nucleotide sequence were not visible on resulting autoradiographs; therefore, it was only possible to directly determine the methylation status of the two CfoI sites and two of nine HpaII sites. Because no fragments larger than those that would be expected from complete digestion of the DNA by HpaII or CfoI were detected, it is reasonable to assume that there is no widespread methylation on either the active or inactive $\mathrm{X}$ chromosome in this region. However, in addition to the HpaII sites that could not be directly tested, many CpG sites were not located within restriction sites.

We used the bisulfite genomic sequencing protocol of Frommer et al. (1992) to analyze the methylation status of all cytosines in the region of highest CpG density. Data are presented for the top strand of DNA only, because any functional DNA methylation must be symmetrical to be inherited stably. Direct cycle sequencing of PCR products amplified from bisulfite-treated DNA from tissues (in which inactivation of the paternally derived allele is complete), cultured fibroblasts (in which partial expression of the paternally derived allele is detectable), and sperm indicated hypomethylation of all cytosines.

These results are supported by the low level of methylation detected by sequencing cloned PCR products. The majority of $\mathrm{CPG}$ dinucleotides 


\section{LOEBEL AND JOHNSTON}

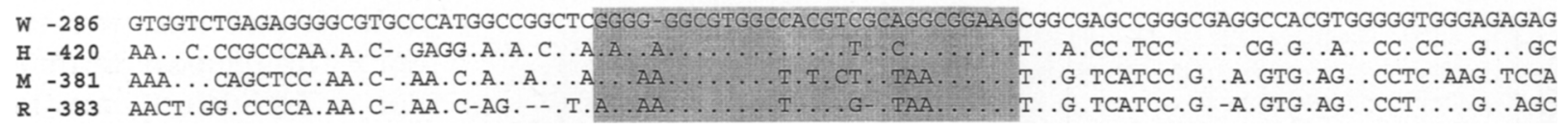

Figure 7 Region of conservation between wallaroo $(w)$, human $(h)$, mouse $(m)$, and rat $(r)$ upstream of exon 1. Dots indicate nucleotides identical to the wallaroo sequence; dashes represent gaps introduced to maximize homology. References for eutherian sequences are given in the text.

were completely unmethylated in all clones sequenced. Although a higher level of methylation was apparent in female liver DNA than in male DNA and half the clones derived from DNA from female liver contained at least one methylated $\mathrm{CpG}$, it is unlikely that this is functional in maintaining $X$ inactivation. If a critical site were present it would be methylated on $50 \%$ of the DNA strands and detected as bands of equal intensity in the $T$ and $C$ lanes when the amplified product was direct sequenced, or by presence of a $\mathrm{C}$ in $50 \%$ of clones. As the maximum number of clones in which any individual cytosine remained unconverted was $2 / 10$ (Fig. 6), these sites are unlikely to be critical sites.

The differences in organization between the CpG islands at the 5' ends of the eutherian (Toniolo et al. 1991) and wallaroo G6PD genes may be related to the different modes of control of G6PD expression from the inactive X. Because there are regions of high conservation between the human and mouse G6PD CpG islands (Toniolo et al. 1991; Rank et al. 1994) that are not present in the wallaroo, it is possible that they are involved in the maintenance of repression of the inactive allele by DNA methylation, a process that does not appear to occur in marsupials.

Kaslow and Migeon (1987) explained the differences in $\mathrm{X}$ inactivation between marsupials and eutherians as the result of differential timing of developmental events. These investigators postulated that because random $X$ chromosome inactivation occurs later in development, after the paternal imprint has been lost, and is stable, whereas paternal $\mathrm{X}$ inactivation in marsupials and eutherians is less stable, differences in methylation state and stability were attributable to differences in developmental timing. Paternal $\mathrm{X}$ inactivation, occurring earlier in development than random $X$ inactivation, would not be stabilized by $\mathrm{CpG}$ methylation. The more recent finding that methylation of critical sites in the G6pd and $P g k-1$ genes occurs in both the embryonic and extraembryonic lineages at or close to the time of initiation of inactivation (Grant et al. 1992) sug- gests that the relationship between the mechanisms of paternal $X$ inactivation in rodent extraembryonic membranes and marsupial tissues is more complex.

Timing of initiation of $\mathrm{X}$ inactivation may differ between marsupials and eutherians. In the mouse, both $X$ chromosomes are potentially active initially, and initiation of $X$ inactivation occurs during preimplantation development (Epstein et al. 1978). In marsupials, there is as yet no evidence for two active $\mathrm{X}$ chromosomes at any time in female development, in either somatic cells or oocytes up to the early dictyate stage (Johnston et al. 1985, 1994; Johnston and Robinson 1987), at which time reactivation of the previously inactive $X$ has occurred in mice (Johnston 1981; Kratzer and Chapman 1981). Initiation of $\mathrm{X}$ inactivation may occur very early in the development of the marsupial embryo; however, data on gene expression and DNA replication patterns during cleavage divisions have so far proved impossible to obtain (Johnston et al. 1994).

Extensive methylation of the active but not the inactive $\mathrm{X}$ within coding and intronic regions has been observed consistently in marsupials in both $D$. virginiana, for HPRT and G6PD (Kaslow and Migeon 1987), and in M. r. robustus for HPRT (Piper et al. 1993) and G6PD (D.A.F. Loebel and P.G. Johnston, unpubl.). Evidence from in situ nick translation experiments suggest this is a chromosome-wide phenomenon (Loebel and Johnston 1993). There is limited evidence that this also occurs in eutherians (Lindsay et al. 1985; Viegas-Pequignot et al. 1988). It is as yet unknown whether this methylation pattern has a role in X chromosome inactivation, but the conservation between divergent taxa and its widespread nature suggests that it may have some function.

This study has confirmed the hypomethylation of $\mathrm{CpG}$ islands on the $\mathrm{X}$ chromosome of marsupials, demonstrating that methylation of CpG islands is probably not a factor in maintaining $\mathrm{X}$ chromosome inactivation marsupials. Cur- 


\section{METHYLATION ANALYSIS OF WALLAROO G6PD}

rent understanding of the mechanisms of $\mathrm{X}$ inactivation in marsupials is very limited. Greater understanding of how $\mathrm{X}$ inactivation occurs in marsupials and its evolutionary relationship to eutherian $\mathrm{X}$ inactivation will only be obtained after more detailed examination of expression and methylation patterns of many more genes in several different species.

\section{METHODS}

\section{Genomic DNA Preparation}

High-molecular-weight DNA was isolated from liver, kidney, spleen, heart, lung, and brain tissue according to Sambrook et al. (1989). Sperm was obtained by cutting the cauda epididymis into small pieces in phosphate-buffered saline (PBS) and allowing the tissue fragments to settle (Venolia et al. 1984). Sperm DNA was isolated following the method of Gill et al. (1985), except that the concentration of SDS was increased to $4.5 \%$ and a total of $8 \mathrm{mg}$ proteinase $\mathrm{K}$ was added to the overnight digestion. Fibroblasts were cultured in Iscove's medium supplemented with $12 \%$ fetal calf serum (Cooper et al. 1977). Cultured fibroblasts were detached from the surface of the culture vessel by incubation with trypsin and resuspended in PBS. DNA was isolated from cultured fibroblasts by a salting-out protocol according to Kunkel (1977).

\section{Library Construction and Screening}

A genomic library was constructed from female $M$. r. robustus liver DNA, partially digested with Sau3AI to produce optimally sized fragments. DNA was ligated into $\lambda \mathrm{GEM}-12$ vector (Promega) and packaged in Packagene (Promega) using the methylation-tolerant PMC128 Escherichia coli as a host strain (Doherty et al. 1993). Phage were plated out at a density of $1 \times 10^{4}$ plaques per plate. Duplicate lifts were made on nitrocellulose membranes (Schleicher \& Schuell). The filters were screened with a PCR product containing exons 2-5 of the wallaroo G6PD cDNA (Loebel et al. 1995). Following electrophoresis in $2 \%$ agarose the electroeluted product was labeled with $\left[\alpha^{32} \mathrm{P}\right] \mathrm{dATP}$ (Bresatec) by random priming (Boehringer). Overnight hybridization and washing were carried out at high stringency $\left(65^{\circ} \mathrm{C}\right)$. After secondary screening, phage DNA was prepared according to Kaslow (1986).

\section{Southern Blotting}

DNA was transferred to Zeta-Probe nylon membrane (BioRad) by alkaline capillary transfer according to the manufacturer's instructions. Blots of digested DNA from the single positive phage clone were probed with digoxigenin (Boehringer)-labeled oligonucleotides specific to exon 2, following the manufacturer's instructions, and also with a PCR product containing the $5^{\prime}$ end of the M. r. robustus G6PD cDNA cloned into the pGEM-T vector and labeled with $\left[\alpha-{ }_{-}^{32}\right.$ P]dATP (Loebel et al. 1995).

For methylation-sensitive restriction enzyme analysis of the CpG island, DNA from M. $r$. robustus was first di- gested with BglII and HindIII followed by MspI, HpaII, or CfoI. Agarose gels $(1.5 \%$ or $2 \%)$ were blotted and probed with pBH1.1, a subcloned fragment from the $\lambda$ clone containing the $\mathrm{CpG}$ island region.

\section{Bisulfite Conversion of DNA}

Bisulfite genomic sequencing was performed according to Clark et al. (1994). DNA (1 $\mu \mathrm{g})$ from male and female tissues, cultured fibroblasts, and sperm was digested for 6-8 hr with BglII in a volume of $10 \mu \mathrm{l}$. A control conversion was also performed on $500 \mathrm{ng}$ of pBH1.1 plasmid DNA, grown in DH5 $\alpha$, and digested with HindIII. DNA was denatured with $0.3 \mathrm{M} \mathrm{NaOH}$ in a volume of $20 \mu \mathrm{l}$ at $37^{\circ} \mathrm{C}$ for $15 \mathrm{~min}$. Sodium metabisulfite and hydroquinone were added to final concentrations of $1.7 \mathrm{M}(3.4 \mathrm{M}$ bisulfite $)$ and $0.5 \mathrm{~mm}$, respectively, in a total volume of $250 \mu \mathrm{l}$. The reaction mixture was incubated in a thermal cycler (MJ Research) for $15 \mathrm{hr}$ at $55^{\circ} \mathrm{C}$ with a 3-min denaturing step at $94^{\circ} \mathrm{C}$ every $3 \mathrm{hr}$. Following the bisulfite reaction, the DNA was desalted using Gene-Clean (Bio 101) or Bresa-Clean (Bresatec). Three volumes of NaI solution and $5 \mu \mathrm{l}$ of Glass milk (Gene-Clean) or silica (Bresa-Clean) were added to the reaction. After washing three times with NEW wash, the DNA was eluted into $45 \mu \mathrm{H}_{2} \mathrm{O}$. Desulfonation of the deaminated cytosines was carried out by adding $5 \mu \mathrm{l}$ of $3 \mathrm{M}$ $\mathrm{NaOH}$ and incubating at $37^{\circ} \mathrm{C}$ for $15 \mathrm{~min}$. The converted DNA was precipitated and resuspended in $100 \mu \mathrm{l}$ of $10 \mathrm{mM}$ Tris- $\mathrm{HCl}$ (pH 7.6), 0.1 mm EDTA (pH8).

\section{Polymerase Chain Reaction}

Amplification by PCR was carried out on $2-5 \mu \mathrm{l}$ of converted DNA in a reaction volume of $25 \mu \mathrm{l}$. Of this reaction, $2-10 \mu \mathrm{l}$ was used directly in a nested reaction with internal primers. Two nested pairs of primers designed from the bisulfite reacted sequence were used. Nested primer combinations used were as follows:

Nested set 1:

External GGS1(forward) TTTAGATATTAAGTTATTTTTTAGAGTATTTG GGS4(reverse) CTAACCCAACCCTTTAACCCCAAACTC

Internal GGS2(forward) GAAGGATTTTTTTTGTTATTTTAAGTGTTT GGS3(reverse) ACTTTAACTCCCATCCAAACCTAAAATTCC

Nested set 2:

External GGS2(forward) As above GGS8 (reverse) ACTTAAATAAAAAAAATCAAAAAACCTAA

Internal GGS6(forward) GGGGTTTTTGGTTAGAGATGGGAGATT GGS7(reverse) ATCTATTAAAATAAAAAACTCAAAACAAAA

Each reaction contained $1.5 \mathrm{mM} \mathrm{MgCl}_{2}, 200 \mu \mathrm{M}$ each deoxynucleoside triphosphate, $1 \mu \mathrm{M}$ each primer, and 1.25 units of Taq polymerase in $1 \times$ reaction buffer (Promega). Cycling conditions were an initial denaturation at $94^{\circ} \mathrm{C}$ 


\section{LOEBEL AND JOHNSION}

for $2 \mathrm{~min}$ followed by five cycles of $94^{\circ} \mathrm{C}$ for $1 \mathrm{~min}, 50^{\circ} \mathrm{C}$ for $2 \mathrm{~min}, 72^{\circ} \mathrm{C}$ for $3 \mathrm{~min}$, then 30 cycles of $94^{\circ} \mathrm{C}$ for 0.5 $\min , 50^{\circ} \mathrm{C}$ for $2 \mathrm{~min}, 72^{\circ} \mathrm{C}$ for $1.5 \mathrm{~min}$, with a final extension of $6 \mathrm{~min}$ at $72^{\circ} \mathrm{C}$. Reactions were incubated in a MJ Research thermal cycler, in thin-walled microtiter plates (MJ Research).

PCR products were size-fractionated in $1.5 \%$ agarose, the slice of gel containing the product excised and the DNA purified with Gene-Clean or Bresa-Clean as described above. Products were resuspended in $10-20 \mu \mathrm{H}_{2} \mathrm{O}$ and either sequenced directly to obtain an average methylation pattern or cloned into pGEM-T vector (Promega) and sequenced to determine the methylation status of individual DNA strands. Cloning and direct sequencing were performed on aliquots of the same PCR reaction.

\section{Sequencing}

Direct sequencing was carried out on $1-3 \mu \mathrm{l}$ of PCR product using the fmol sequencing system (Promega), with ${ }^{32} \mathrm{P}$ end-labeled primers identical to the internal primers used in the nested PCR reaction.

Double-stranded plasmid DNA was prepared from overnight bacterial cultures by alkaline lysis (Sambrook et al. 1989) and sequenced using T7 polymerase (Sequenase, U.S. Biochemical). M13/pUC forward and reverse sequencing primers or specific primers for direct sequencing were used.

\section{ACKNOWLEDGMENTS}

We thank J. Doherty for kindly providing the bacterial strain PMC128; S. Clark and J. Harrison for assistance with genomic sequencing; and D. Cooper, J. Donald, M. Frommer, K. Humphrey, C. Metcalfe, and C. Watson for comments on draft versions of this paper. We also thank $\mathrm{R}$. Claassens, S. McLeod, and R. Moore for assistance with care and handling of the animals. This research was supported by grants from the Australian Research Council and Macquarie University Research Grants scheme to P.G.J. D.A.F.L. is the recipient of an Australian Postgraduate Research Award. Sequence data described in this paper have been deposited with GenBank and assigned accession number U34997.

The publication costs of this article were defrayed in part by payment of page charges. This article must therefore be hereby marked "advertisement" in accordance with 18 USC section 1734 solely to indicate this fact.

\section{REFERENCES}

Clark, S. J., J. Harrison, C.L. Paul., and M. Frommer. 1994. High sensitivity mapping of methylated cytosines. Nucleic Acids. Res. 22: 2990-2997.

Cooper, D.W., C. Edwards, E. James, G.B. Sharman, J.L. VandeBerg, and J.A.M. Graves. 1977. Studies on metatherian sex chromosomes VI. A third state of an X-linked gene: Partial activity for the paternally derived Pgk-A allele in Macropus giganteus and M. parryi. Aust. J. Biol. Sci. 30: 431-443.
Doherty, J.P., R.T. Lindeman, R.J. Trent, M.W. Graham, and D.M.Woodcock. 1993. Escherichia coli host strains SURE $^{\mathrm{TM}}$ and SRB fail to preserve a palindrome cloned in lambda phage: Improved alternate strains. Gene 124: $29-35$.

Epstein, C.J., S. Smith, B. Travis, and G. Tucker. 1978. Both $\mathrm{X}$ chromosomes function before visible $\mathrm{X}$ chromosome inactivation in female mouse embryos. Nature 274: 500-503.

Frommer, M., L.E. McDonald, D.S. Millar, C.M. Collis, F. Watt., G.W. Grigg, P.L. Molloy, and C.L. Paul. 1992. A genomic sequencing protocol that yields a positive display of 5-methylcytosine residues in individual DNA strands. Proc. Natl. Acad. Sci. 89: 1827-1831.

Gardiner-Garden, M. and M. Frommer. 1987. CpG islands in vertebrate genomes. J. Mol. Biol. 196: 261-282.

Gill, P., A.J. Jeffreys, and D.J.Wherret. 1985. Forensic applications of DNA fingerprints. Nature 318: 577-578.

Grant, M., M. Zuccotti, and M. Monk. 1992. Methylation of $\mathrm{CpG}$ sites of two X-linked genes coincides with $\mathrm{X}$ inactivation in the female mouse embryo but not the germ line. Nature Genet. 2: 161-166.

Grigg G. and S.Clark. 1994. Sequencing 5-methylcytosine residues in genomic DNA. BioEssays 16: $431-436$.

Hansen, R.S., N.A. Ellis, and S.M. Gartler. 1988. Demethylation of specific sites in the $5^{\prime}$ region of the inactive $\mathrm{X}$-linked human phosphoglycerate kinase gene correlated with the appearence of nuclease sensitivity and gene expression. Mol. Cell. Biol. 8: 4692-4699.

Hornstra, I.K. and T.P.Yang. 1994. High resolution methylation analysis of the human hypoxanthine phosphoribosyltransferase gene $5^{\prime} \mathrm{CpG}$ region on the active and inactive $\mathrm{X}$ chromosome: Correlation with binding sites for transcription factors. Mol. Cell. Biol. 14: 1419-1430.

Johnston, P.G. 1981. X chromosome activity in female germ cells of mice heterozygous for Searle's translocation $\mathrm{T}(\mathrm{X} ; 16) 16 \mathrm{H}$. Genet. Res. 37: 317-322.

Johnston, P.G. and E.S. Robinson. 1987. X chromosome inactivation in female embryos of a marsupial mouse (Antechinus stuartii). Chromosoma 95: 419-423.

Johnston, P.G., E.S. Robinson, and D.M. Johnston. 1985. Dictyate oocytes of a kangaroo (M. robustus) show paternal inactivation at the X-linked Gpd locus. Aust. J. Biol. 38: 79-84.

Johnston, P.G., D. Dean, J.L. VandeBerg, and E.S. Robinson. 1994. HPRT activity in embryos of a South American opossum Monodelphis domestica. Reprod. Fertil. Dev. 6: 529-532.

Kaslow, D.C. 1986. A rapid biochemical method for 


\section{METHYLATION ANALYSIS OF WALLAROO G6PD}

purifying lambda DNA from phage lysates. Nucleic Acids Res. 14: 6767.

Kaslow, D.C. and B.R. Migeon. 1987. DNA methylation stabilizes $\mathrm{X}$ chromosome inactivation in eutherians but not marsupials: Evidence for multistep maintenance of mammalian dosage compensation. Proc. Natl. Acad. Sci. 84: $6210-6214$.

Kratzer, P.G and V.M. Chapman. 1981. X chromosome reactivation in oocytes of Mus caroli. Proc. Natl. Acad. Sci. 78: 3093-3097.

Kunkel, L.M. 1977. Analysis of human Y-chromosome specific reiterated DNA in chromosome variants. Proc. Natl. Acad. Sci. 74: 1245-1249.

Lindsay, S., M. Monk, R. Holliday, L. Huschtscha, K.E. Davies, A.D. Riggs, and R.A. Flavell. 1985. Differences in methylation on the active and inactive human $\mathrm{X}$ chromosomes. Ann. Hum. Genet. 49: 115-127.

Loebel, D.A. and P.G. Johnston. 1993. Analysis of DNase 1 sensitivity and methylation of active and inactive $\mathrm{X}$ chromosomes of kangaroos (Macropus robustus) by in situ nick translation. Chromosoma 102: 81-87.

Loebel, D.A.F., T.J. Longhurst, and P.G. Johnston. 1995. Full length cDNA sequence of X-linked G6PD of an Australian marsupial, the wallaroo. Mammal. Genome 6: $198-201$.

Norris, D.P., N. Brockdorff, and S. Rastan. 1991. Methylation status of $\mathrm{CpG}$ rich islands on the active and inactive X chromosomes. Mammal. Genome 1: 78-83.

Park, J.G. and V.M. Chapman. 1994. CpG island promoter region methylation patterns of the inactive $\mathrm{X}$ chromosome hypoxanthine phosphoribosyltransferase (HPRT) gene. Mol. Cell. Biol. 14: 7975-7983.

Pfeiffer, G., S.D. Steigerwald, R.S. Hansen, S.M. Gartler, and A.D. Riggs. 1990. Polymerase chain reaction-aided genomic sequencing of an X chromosome linked CPG island: Methylation patterns suggest clonal inheritance, CpG site autonomy, and an explanation of activity state stability. Proc. Natl. Acad. Sci. 87: 8252-8256.

Piper, A.A., A.M. Bennett, L. Noyce, M.K. Swanton, and D.W. Cooper. 1993. Isolation of a clone partially encoding Hill kangaroo X-linked hypoxanthine phosphoribosyltransferase: Sex differences in methylation in the body of the gene. Somat. Cell Mol. Genet. 19: 141-159.

Rank, K.B., P.K. Harris, L.C. Ginsberg, and S.R. Stapleton. 1994. Isolation of a rat glucose-6-phosphate dehydrogenase promoter. Biochim. Biophys. Acta 1217: 90-92.

Sambrook, J., E.F. Fritsch, and T. Maniatis. 1989. Molecular cloning: A laboratory manual, 2nd ed. Cold Spring Harbor Laboratory Press, Cold Spring Harbor, New York.
Sharman, G.B. 1971. Late DNA replication in the paternally derived $\mathrm{X}$ chromosome of female kangaroos. Nature 230: 231-232.

Singer-Sam, J. and A.D. Riggs. 1993. X chromosome inactivation and DNA methylation. In DNA methylation: Molecular biology and biological significance (ed. J.P. Jost and H. Saluz), pp. 169-185. Birkhauser Verlag, Basel, Switzerland.

Singer-Sam, J., M. Grant, J.M. Le Bon, K. Okuyama, V. Chapman, M. Monk, and A.D. Riggs. 1990. Use of a HpaII sensitive polymerase chain reaction to study DNA methylation in the $P g k-1$ gene at the time of $\mathrm{X}$ chromosome inactivation. Mol. Cell. Biol. 10: 4987-4989.

Tommasi, S., J.M. LeBon, A.D. Riggs, and J. Singer-Sam. 1993. Methylation analysis by genomic sequencing of the $5^{\prime}$ of mouse $P g k-1$ gene and a cautionary note concerning the method. Somat. Cell. Mol. Genet. 19: $529-541$.

Toniolo, D., M. Fillipi, R. Dono, T. Lettieri, and G. Martini. 1991. The CpG island in the $5^{\prime}$ region of the G6PD gene of man and mouse. Gene 102: 197-203.

VandeBerg, J.L., E.S. Robinson, P.B. Samollow, and P.G. Johnston. 1987. X-linked gene expression and X chromosome inactivation: Marsupials, mouse and man compared. Isozymes 15: Genetics, development and evolution. Alan R. Liss, New York. pp. 225-253.

Venolia, L., D.W. Cooper, D.A. O'Brien, C.F. Millette, and S. Gartler. 1984. Transformation of the Hprt gene with DNA from spermatogenic cells. Implications for the evolution of dosage compensation. Chromosoma 90: $185-189$.

Viegas-Pequignot, E., B. Dutrillaux, and G. Thomas. 1988. Inactive X chromosome has the highest concentration of unmethylated HhaI sites. Proc. Natl. Acad. Sci. 85: 1657-1660.

West, J.D., W.I. Frels, V.M. Chapman, and V.E. Papaioannou. 1977. Preferential expression of the maternally derived $X$ chromosome in the mouse yolk sac. Cell 12: 873-882.

Received October 3, 1995; accepted in revised form February 1, 1996. 


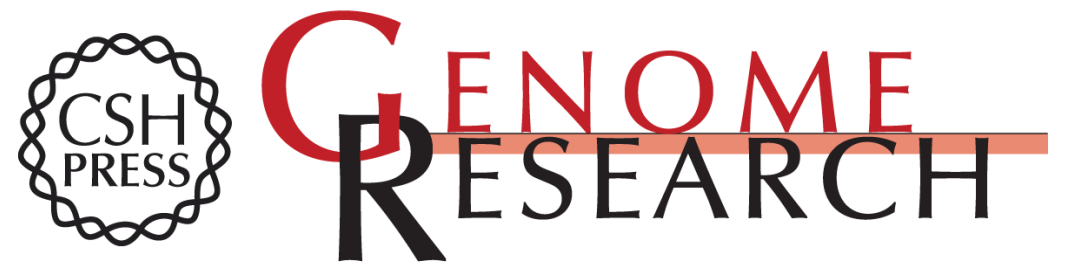

\section{Methylation analysis of a marsupial X-linked CpG island by bisulfite genomic sequencing.}

D A Loebel and P G Johnston

Genome Res. 1996 6: 114-123

Access the most recent version at doi:10.1101/gr.6.2.114

References This article cites 34 articles, 10 of which can be accessed free at:

http://genome.cshlp.org/content/6/2/114.full.html\#ref-list-1

\section{License}

Email Alerting Receive free email alerts when new articles cite this article - sign up in the box at the Service top right corner of the article or click here.

\section{Affordable, Accurate Sequencing.}

To subscribe to Genome Research go to:

https://genome.cshlp.org/subscriptions 